\title{
Assessment of Consumer Preference Regarding Developed Re-usable Face Mask as a Preventive Tool against COVID-19
}

\author{
Nabaneeta Gogoi*, Parishmita Neog and Dibyashree Saikia
}

All India Coordinated Research Project on Home Science, Department of Textiles and Apparel Designing, College of Community Science, Assam Agricultural University, Jorhat, India

*Corresponding author

\section{A B S T R A C T}

\section{Keyw ords}

Face mask, Reusable, Suitability, Breathability, Income

\section{Article Info}

Accepted: 04 September 2020 Available Online: 10 October 2020
Now-a-days, wearing a mask is becoming a part of a comprehensive package of the prevention that can reduce the spread of COVID-19 and other respiratory viral diseases. Mask can play a vital role in protection of a healthy individual or in control of source of transmission. The present study was conducted to assess the preferences of developed re-usable face mask (D1, D2, D3) in respect of its different features such as comfort, breathability, suitability, size, shape, fitting and design of the face mask and the study revealed that D3 has got the highest $(70 \%)$ consumer preference. $100 \%$ of the respondents agreed that making face mask can be a profitable source of income generation.

\section{Introduction}

COVID-19 is a severe respiratory illness caused by a novel corona virus called SARSCoV-2. As Corona virus has become a global pandemic, there have been widespread changes to daily life to stop the spread of the virus that at present has no cure. Changes to prevent the spread of the virus have included physical and social distancing, more rigorous hygiene practices, and wearing protective facial coverings. Within a short period, Covid-19 has evolved into a global pandemic. The base of this pandemic is that it can be transmitted from one to another through droplets, so it was quickly and clearly understood that prevention is the main key to stop this pandemic.

In recent time public health experts have focused on the importance of wearing face masks as a weapon againstCovid-19. Face mask or face coverings act as a barrier by protecting the individual from getting infected by another person. The global pandemic COVID-19 has led to a shortage of medical mask around everywhere. As a basic nonpharmaceutical intervention (NPI) measure, 
wearing a mask is an effective source of preventing respiratory infectious diseases, which could reduce the risk of infection (World Health Organization Writing Group 2006).

According to CDC (Centre for disease control and prevention) recommendation, all people should wear a cloth face covering in public settings and when around people who don't live in our household, especially when other preventive measures like physical and social distancing are difficult to maintain. People who do not have any symptoms of COVID-19 can be a spreader of these diseases. That's why it's important for everyone to wear cloth face coverings in public settings and practice social distancing (staying at least 6 feet away from other people).

A research paper published in "Science of the Total Environment" highlighted that Cotton mask can reduce respiratory droplet transmission. There are no significant differences between medical or surgical mask and homemade cotton mask for prevention of droplet. Accordingly, their findings may suggest that cotton mask could be a potential substitute for medical or surgical mask for respiratory infection.

In addition to that they also mentioned that, a healthy person may daily use cotton mask in the public area since cotton mask is washable and reusable. The shortage of disposable medical masks could be expected during a pandemic respiratory infection

Self-cleaning is becoming a desirable feature in case of face mask. A disposable mask is usually not environment-friendly and requires continuous manufacturing and purchasing. Whereas home-made cotton mask are washable and reusable. According to a new study from Oxford's Leverhulme Centre for Demographic Science, cloth face coverings or homemade masks made of the correct material are very much effective in reducing the spread of COVID-19 for the wearer as well as those around them. The study says that people should wear a mask to reduce virus transmission and protect themselves.

The study also found that, behavioural factors like how people understand the virus and their perceptions of risk, rust in experts and government are involved which can adversely affect mask wearing.

Different types of face masks provide different levels of protection to the wearer. The global pandemic Covid-19 has resulted in a shortage of face masks and the raw materials required for them, resulting in self producing of face mask from available household materials.

Face masks need to be covered as part of 'policy packages' with other preventive measures such as hand hygiene, physical and social distancing. Clear and consistent policies and awareness in public are the means that can help for adoption of wearing face masks and coverings by the general public. Though there are many varieties of masks available in the market, not all the masks are as protective as it needs to be.

The global pandemic has led to a shortage of medical mask around everywhere. Many branded companies have started producing face mask, but these are out of reach for common people due to its high cost. Keeping in view the importance of affordable and reusable face mask, the investigator has developed three different face masks to assess the preference of the consumer regarding the developed face mask in respect of design as well as other important features of the face mask. 


\section{Materials and Methods}

Locale of the study: The study was conducted among the working women of Assam Agricultural University, Jorhat.

Selection of raw material: $100 \%$ cotton fabric of both plain and printed of GSM 1.01g was selected for the face mask. Details of the selected fabrics are given in Table 1. Elastic of $1 / 4^{\text {th }}$ inch of white colour was used for the study.

Selection of design: Three designs of two layered face mask were selected for the study and the designs were coded as D1, D2 and D3.

D1: Pleated face mask (Plate 1): It is a rectangular shaped and pleated with knife pleats. Its size was $22 \mathrm{~cm} \mathrm{X} 8 \mathrm{~cm}$ (finished excluding elastics).

D2: Face mask with dart (Plate 2): Darts were applied in the centre of the mask on both top and bottom side. Its size was $24 \mathrm{~cm} \mathrm{X} 14$ $\mathrm{cm}$ (finished excluding elastics).

D3: Shaped face mask (Plate 3): It has a shaped in the centre of the top side. Its size $\begin{array}{llllll}\text { was } 24 & \mathrm{~cm} & \mathrm{X} & 14 & \mathrm{~cm} & \text { (finished }\end{array}$ excluding elastics).
Drafting of mask was carried out by drawing the outline of the mask. Standard measurements were considered for drafting the mask.

\section{Stitching of face mask}

Face masks were stitched in the Department of Textiles and Apparel Designing, College of Community Science, Assam Agricultural University, Jorhat. Two elastics were attached at each corner of the mask.

\section{Collection of data}

A well-structured questionnaire was prepared to assess the preferences of the mask. The prepared masks were provided to the respondents along with the questionnaire. They were asked to use the masks and give feedback through the questionnaire after 10 days.

Analysis of data: Weighted mean scores were calculated for each attribute of the developed face masks. Five different scores $(5,4,3,2,1)$ were given for excellent, very good, good, fair and poor respectively. Weighted mean score (WMS) were calculated from the number of respondent against each attribute of the developed face masks.

\section{Drafting of face mask}

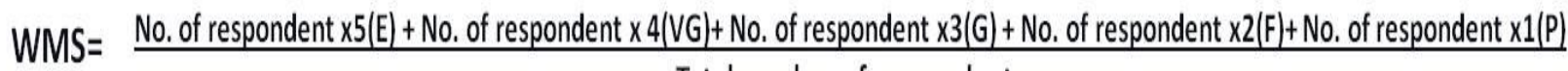
Total number of respondents

No. of respondent $=$ Number against each attributes E=Excellent, VG=Very good, $\mathrm{G}=$ Good, $\mathrm{F}=$ Fair, $\mathrm{P}=$ Poor

\section{Findings}

The developed two layered cotton masks were evaluated by the working women of Assam
Agricultural University, Jorhat. All the respondents belong to the age group of 50-64 years. They were asked several questions regarding face mask along with other preventive measures to be followed during this Covid-19 pandemic period. 
Assessment of preventive measures followed by the respondents

Regarding preventive measures followed by the respondents, the study found that $100 \%$ of the respondents were aware about the preventive measures to be followed during Covid-19 pandemic. Among the preventive measures, $100 \%$ of the respondents used to wear face mask, maintain social distancing and wash their hands frequently. Along with these preventive measures $90 \%$ of them used to take nutritious diet and $30 \%$ take medicine as the preventive measures (Fig. 1).

All the respondents $(100 \%)$ think that wearing a mask can help to reduce the spread of Corona virus. Along with this $80 \%$ of them feels that wearing a mask does not make them feel less likely to follow the social distancing guidelines.

Regarding number of mask used daily, 70\% of the respondents wear only one mask during a day whereas $30 \%$ of the respondents wear 2 masks in a day.

\section{Assessment of preferences of face mask}

Regarding preferences of face mask, it was cleared from the fig. 2 that, $60 \%$ of the respondents prefer homemade mask while $30 \%$ prefer readymade mask and $10 \%$ of them prefers both homemade and readymade mask. They also mentioned the reasons why they prefer the homemade mask. They found it more comfortable, washable and easy to wear (Fig. 2). Results also revealed that $90 \%$ of the respondents prefer matching face mask with their outfit.

\section{Preferences of Materials and fabric for face mask}

From the fig. $3 \mathrm{a}$ and fig. $3 \mathrm{~b}$ it was revealed that in case of material for face mask, $90 \%$ of the respondents prefer cotton material whereas $10 \%$ of them prefer blended material. Also $90 \%$ of them prefer both plain and printed fabric whereas $10 \%$ of them prefer only printed fabric for face mask (Fig. 3a and Fig. 3b).

\section{Preference of important features for face mask}

Regarding preference of important features in case of selection of face mask, $90 \%$ of the respondents prefer size of the face mask, $70 \%$ of them prefer shape and fabric texture whereas $40 \%$ of the respondents prefer colour and design. Only $20 \%$ prefer price of the face mask (Fig. 4).

\section{Assessment of care of face mask}

Regarding care of face mask, $80 \%$ of the respondents wash their face mask immediately after every use. From the fig. 5 it was cleared that $50 \%$ of the respondents use soap and water, $30 \%$ use soap and water along with dettol whereas $20 \%$ of them use hot water with dettol to wash their face mask. (Fig. 5).

In case of removal of face mask all of the respondents $(100 \%)$ remove their mask by holding the stripe. $60 \%$ of the respondents washes their hands before putting on and off the face mask. For drying of face mask $90 \%$ follows sun drying whereas $10 \%$ follow shade drying.

\section{Assessment of different features of the developed face masks}

To assess the different features of the developed masks WMS was calculated. From the table 1 it was noticed that in case of size, highest and equal WMS (4.1) was found in D2 and D3. Regarding shape of the developed face mask, highest WMS (4.3) was found in D3 followed by D2 (4.1) and D1 (3.6) respectively. In case of fabric, highest and 
equal WMS (4.1) was found in D2 and D3 followed by D1 (3.3) respectively. Regarding fitting of the developed face masks, highest WMS (4.2) was found in D3 followed by D2 (4.1) and D1 (3.4) respectively. Regarding comfort, highest WMS (4.4) was found in D3 followed by D2 (4.1) and D1 (3.1) respectively. In case of breathability of the developed face masks, highest WMS (4.2) was found in D3 followed by D2 (4.1) and D1 (3.3) respectively.

Table.1 Assessment of features of the developed face masks

\begin{tabular}{|c|c|c|c|c|c|c|c|c|}
\hline Design & $\begin{array}{c}\text { Size } \\
\text { (WMS) }\end{array}$ & $\begin{array}{c}\text { Shape } \\
\text { (WMS) }\end{array}$ & $\begin{array}{c}\text { Fabric } \\
\text { (WMS) }\end{array}$ & $\begin{array}{c}\text { Fitting } \\
\text { (WMS) }\end{array}$ & $\begin{array}{c}\text { Comfort } \\
\text { (WMS) }\end{array}$ & $\begin{array}{c}\text { Breathability } \\
\text { (WMS) }\end{array}$ & \multicolumn{2}{c|}{$\begin{array}{c}\text { Suitability } \\
\text { (WMS) }\end{array}$} \\
\hline D1 & 3.6 & 3.6 & 3.3 & 3.4 & 3.1 & 3.3 & 3.6 & Re-use \\
Both side use \\
\hline D 2 & 4.1 & 4.1 & 4.1 & 4.1 & 4.1 & 4.1 & 4.2 & 4.3 \\
\hline D 3 & 4.1 & 4.2 & 4.1 & 4.2 & 4.4 & 4.2 & 4.5 & 4.3 \\
\hline
\end{tabular}

Fig.1 Assessment of preventive measure followed by the respondents

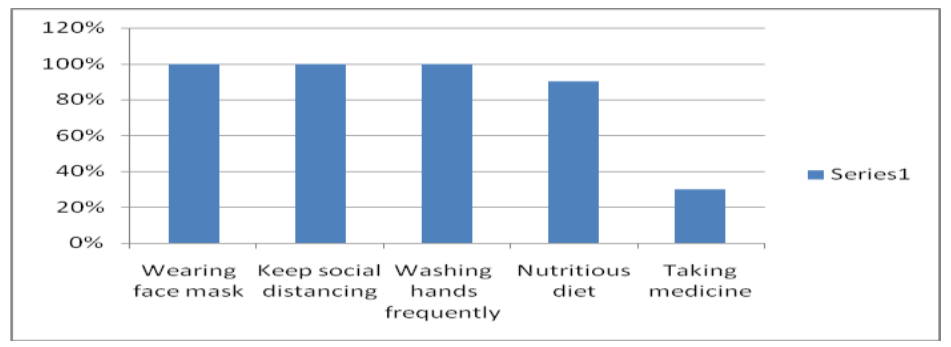

Fig.2 Preferences of face mask

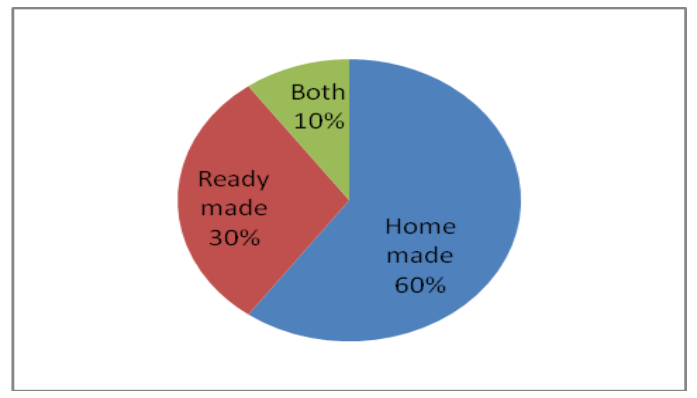

Fig.3a Preferences of materials

Fig.3b Preferences of fabric
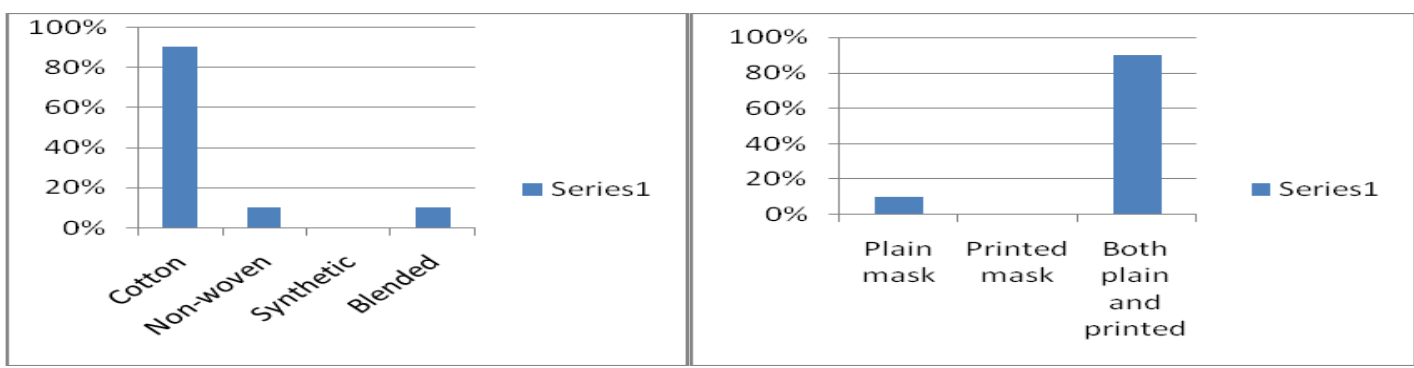
Fig.4 Preference of important features for face mask

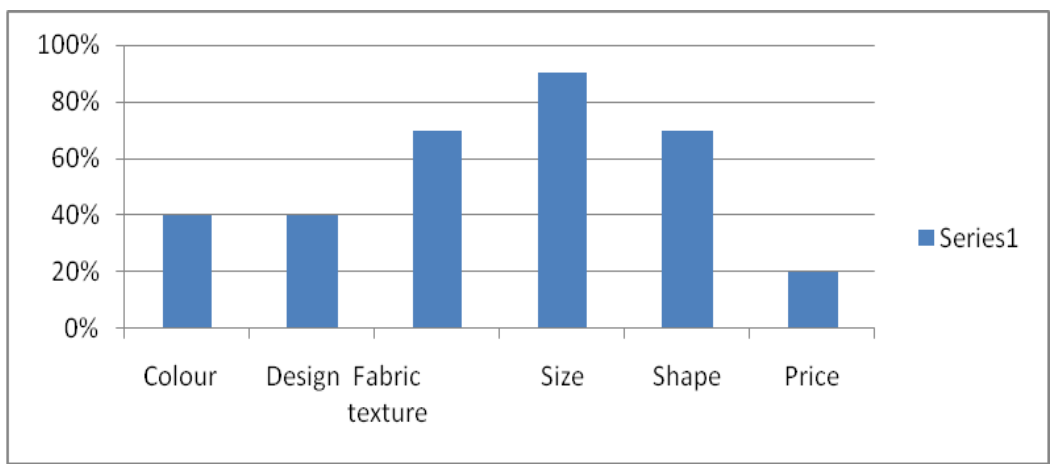

Fig.5 Washing of face mask

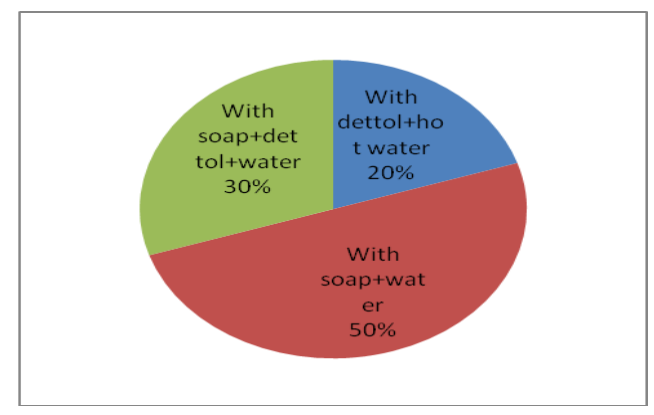

Fig.6 Preference of face mask design

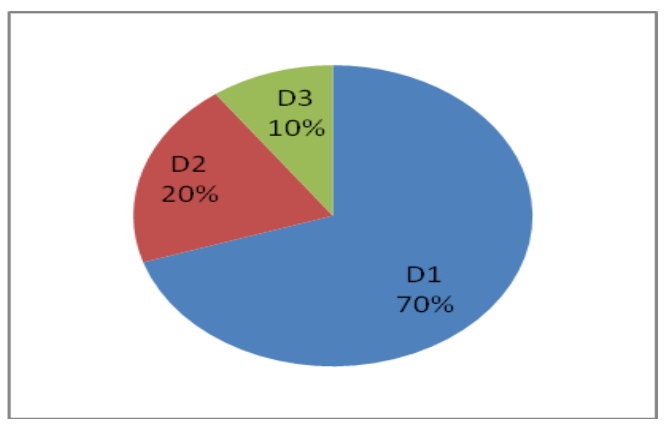

Plate.1 Pleated face mask (D1)

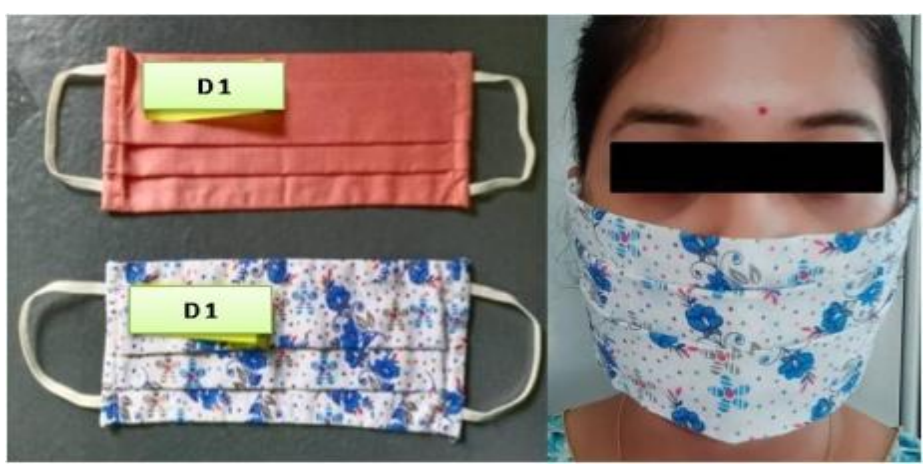


Plate.2 Face mask with dart (D2)

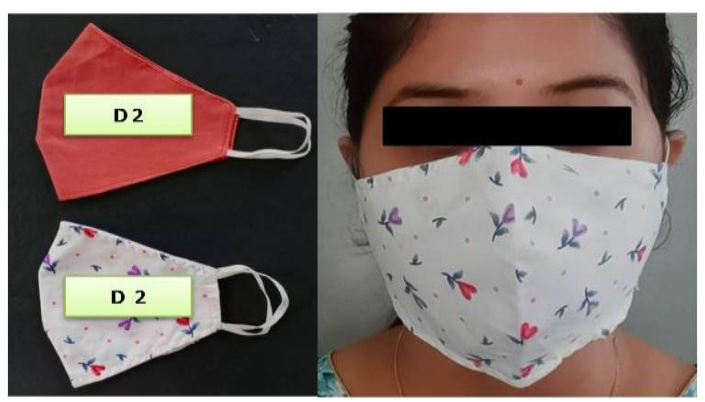

Plate.3 Shaped face mask (D3)

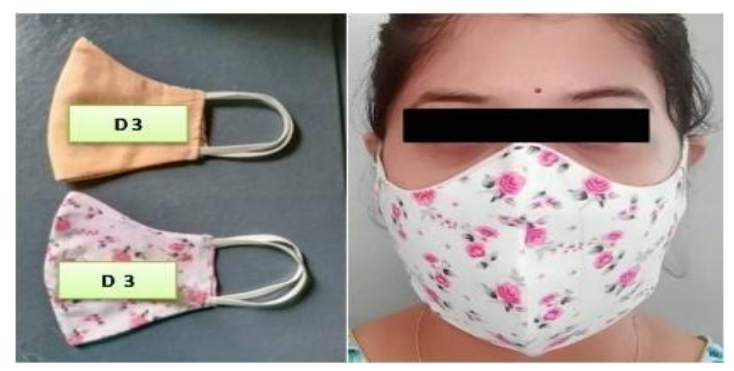

Plate.4 Face mask with Design 3 (D3)
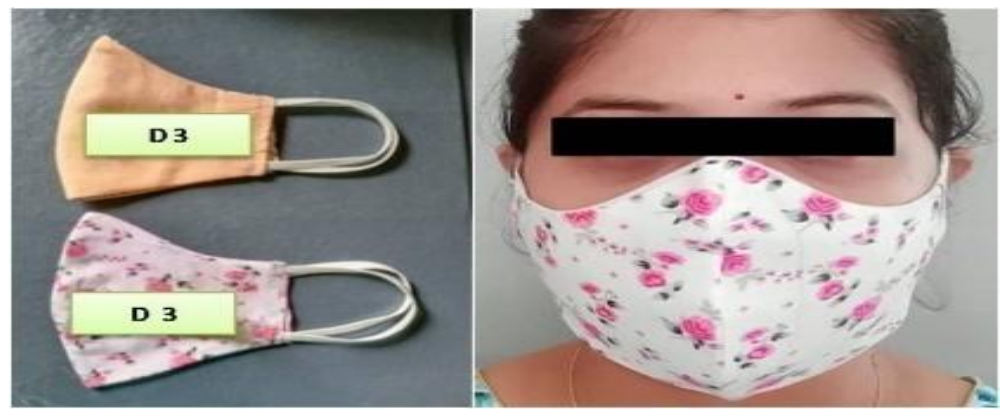

Plate.5 Drafting of the Design 3

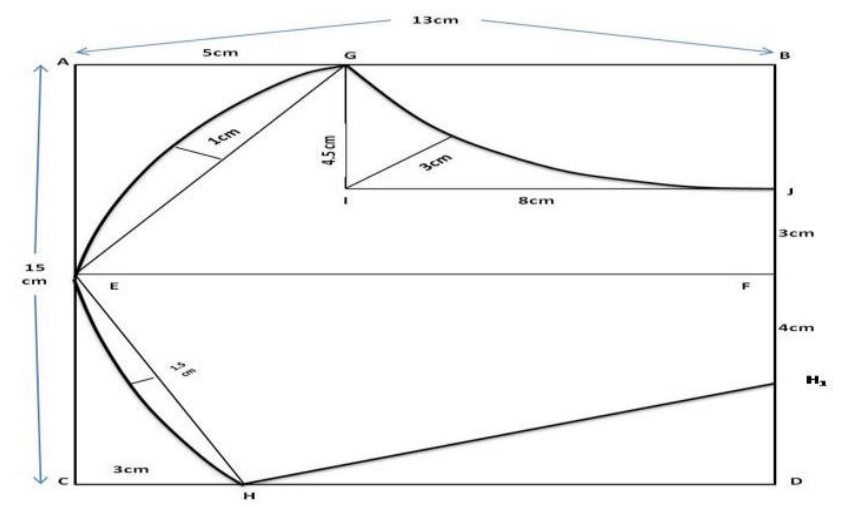


Regarding the suitability of the developed face masks in terms of re-use, highest WMS (4.5) was found in D3 followed by D2(4.2) and D1 (3.6) respectively. In case of both side use highest WMS (4.3) was found in D3 followed by D2 (4.0) and D1 (3.3) respectively. More over among all the developed face masks, D3 scored the highest WMS in almost all the features (Table 1).

\section{Preference of face mask design}

Among the design of the face mask, $70 \%$ respondents found D3 as best among the three developed re-usuable face mask. Whereas $20 \%$ of the respondents prefer D2 and $10 \%$ prefer D1. Hence, it can be said that D3 (Shaped face mask) is found to be best design for face mask (Fig. 6).

\section{Drafting instruction for Design 3}

$\mathrm{AB}=\mathrm{CD}=13 \mathrm{~cm}$

$\mathrm{AC}=\mathrm{BD}=15 \mathrm{~cm}$

$\mathrm{AE}=\mathrm{EC}=7.5 \mathrm{~cm}$

$\mathrm{BF}=\mathrm{FD}=7.5 \mathrm{~cm}$

$A G=5 \mathrm{~cm}$, Join $\mathrm{G}$ and $\mathrm{E}$ with a straight line.

Make a smooth curve from $\mathrm{G}$ to $\mathrm{E}$ keeping 1 cm outside the line GE.

$\mathrm{CH}=3 \mathrm{~cm}$, Join $\mathrm{E}$ and $\mathrm{H}$ with a straight line. Make a smooth curve from $\mathrm{E}$ to $\mathrm{H}$ keeping $1.5 \mathrm{~cm}$ outside the line $\mathrm{EH}$.

$\mathrm{FH}_{1}=4 \mathrm{~cm}$, Join $\mathrm{H}$ and $\mathrm{H}_{1}$ with a straight line.

$\mathrm{GI}=4.5 \mathrm{~cm}, \mathrm{IJ}=8 \mathrm{~cm}$, Now make a smooth curve from $\mathrm{G}$ to $\mathrm{J}$ keeping $3 \mathrm{~cm}$ apart from the point I making an angle of $45^{\circ}$ from the line IJ.

Seam allowances of $1 / 2 \mathrm{~cm}$ were included in all sides.

\section{Stitching instruction for Design 3}

Cut four pieces of cotton fabric according to the drafting pattern and two pieces of elastic of 6" (inch).

Join the curved lines separately for making two pieces.

Attach the elastics (2 pieces) at corners of right side of the fabric (piece 1) keeping the elastic towards centre.

Place the other piece of fabric (piece 2) on top of it facing the right side and join together. Keep unstitched at one part for about two inches for turning the stitched pieces to the right side.

Turn the pieces to the right side and finish with a top stitch all around the mask.

\section{Income generation through face mask}

$100 \%$ of the respondents felt that making face mask can be a profitable source of income generation and for that specialised skills like hand and machine stitching, cutting and measuring skills are important.

From the study it was revealed that different features of a face mask influence the consumer in selecting the appropriate face mask. Study showed that D3 found to be highly preferred face mask design along with its other features. D3 got highest WMS in comfort (4.4), breathability (4.2), suitability (4.5), fitting (4.2) and shape (4.2) respectively. In this recent period of Covid-19 pandemic, wearing a mask is becoming a part of our daily clothing attire and it is proved from the study that $90 \%$ of the respondents prefer matching face mask with their outfit.

Present study also reveals that the making masks of different types may be a source of income generating activity during and after pandemic. $100 \%$ of the respondents agreed that making face mask can be a profitable source of income and specialised skills like 
hand and machine stitching, cutting and measuring are required and training also can be imparted regarding mask making, so that jobless youth can take up it as their earning source.

\section{References}

Aggarwal N. et al., 2020. Facemasks for prevention of viral respiratory infections in community settings: A systematic review and meta-analysis. Indian Journal of public Health. Vol64, Issue-6, pp-192-200.

Chua M.H. et al., 2020. Face masks in the new normal: Materials, Testing, and Perspectives. Research A science Partner journal. Vol-2020, article ID 7286735. https://doi.org/10.34133/2020/7286735

Ho K. F. et al., 2020. Medical mask versus cotton mask for preventing respiratory droplet transmission in micro environments. Science of the Total Environment. Vol- 735, pp-139-510.

Mills M. 2020. Oxford COVID-19 study: face masks and coverings work - act now. Oxford's Leverhulme Centre for Demographic Science.

Nonpharmaceutical Interventions for Pandemic Influenza, National and Community Measures. World Health Organization Writing Group.

Panda R. et al., 2020. Covid-19 mask: A modified anatomical face mask. Indian Journal of Anasthesia. Vol-64, Issue14, pp-144-45

Ramakrishnan D. 2020. Covid-19 and face mask- To use or not to use. Indian Journal of Community Health. Vol: 32

Sra et al., 2020. Use of face masks in Covid19. Indian Journal of Pediatrics. Vol87, Issue-7.

\section{How to cite this article:}

Nabaneeta Gogoi, Parishmita Neog and Dibyashree Saikia. 2020. Assessment of Consumer Preference Regarding Developed Re-usable Face Mask as a Preventive Tool against COVID19. Int.J.Curr.Microbiol.App.Sci. 9(10): 353-361. doi: https://doi.org/10.20546/ijcmas.2020.910.044 